\title{
A pastoral psychological approach to domestic violence in South Africa
}

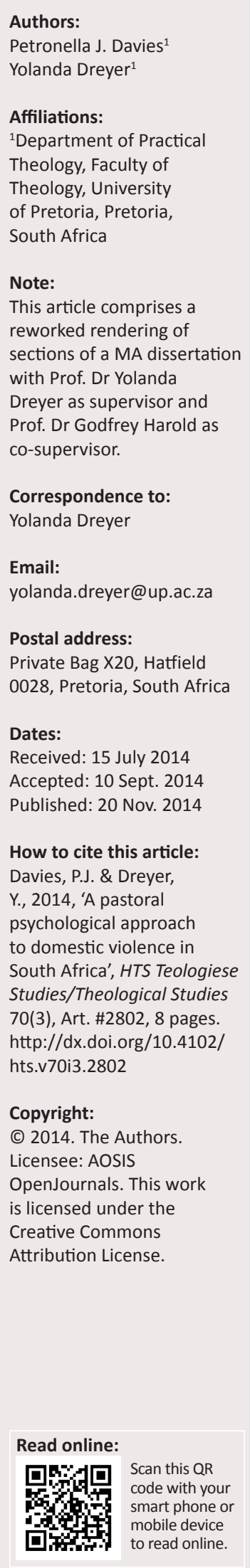

South Africa suffers a scourge of domestic violence. Colonial oppression upset the delicate balance between 'discipline' and 'protection' in traditional cultures. The full consequence of a patriarchal mindset of male control is unleashed on girls and women. The aim of this article is to investigate how the cycle of domestic violence can be broken and what role pastoral counsellors can play with regard to both victims and offenders in order to prevent history from repeating itself. The article also investigates the extent to which legislation has succeeded in protecting individuals. Pastoral care and counselling comprise both spiritual and emotional support. The combination of two counselling methods compatible with religious themes such as 'hope' and 'new life', namely logotherapy (Victor Frankl) and narrative pastoral counselling, is presented as an effective response to domestic violence.

\section{Violence affects the whole person}

Many South African citizens have experienced violence first-hand. According to De Beer (2007:6) South Africa is the second most unsafe country out of the 48 countries south of the Sahara. This is evident by the walled enclosures and electric fencing in cities. The high rate of domestic violence in South Africa and the emotional disturbances that are often the consequence call for a theological response. The aim of this article is to investigate how the cycle of domestic violence can be broken and what role pastoral counsellors can play with regard to both victims and offenders in order to prevent history from repeating itself. People who suffer emotional disturbances as a result of domestic abuse are affected in mind, body and spirit and their social lives are also disrupted (Collins \& Culbertson 2003:1,3). They are in need of healing and support. The complex psychological and emotional disturbances that often plague their later lives have to be managed.

Since Sigmund Freud ([1948] 1964) it has been a common assumption that people who suffer from psychological afflictions can be helped by speaking about it. If the root cause could be uncovered and acknowledged, victims can deal with their emotions and the effects of the incident(s) (Capps 2010:1). Pastoral theologian Donald Capps (2010:2) explores the power of words to affect healing. He uses miracles of Jesus as an example of how words were utilised to help victimised individuals. Capps (2010:3) does not regard Jesus as a 'magician', but emphasises that words do have power. This study investigates how the power of words can contribute to helping people with emotional disturbances caused by domestic violence today. They have the need to talk and be listened to in order to be healed.

Pastoral care and counselling comprise both spiritual and emotional support. Emotional disturbances can lead to a loss of faith and the hope of a right relationship with God. The effects of domestic violence and abuse include self-hatred, guilt, despair and self-annihilation. The loss of a sense of reality can manifest in self-importance, grandiosity and fear. Religious and non-religious support structures, and ritual and community life can contribute to the recovery of people who have been victimised by the perpetrators of violence. The guidance given by a pastoral counsellor focuses on helping individuals to function at an acceptable cognitive and moral level in their thinking, attitudes, emotions and behaviour. The pastor is often approached when a situation has already escalated and emotions are complex. It could be necessary for the pastoral counsellor and the abused person to work together with a psychiatrist or a psychologist. The aim is to guide the individual out of darkness into a right relationship with him- or herself, the world and God (Collins \& Culbertson 2003:4-6). Human beings are driven by a 'will to meaning' even under the worst circumstances. According to psychologist Victor Frankl ([1946] 2004:76-85, 104-105), who did ground-breaking work on the meaning of life during and after the Second World War, discouragement can be overcome by creating something or an action, by experiencing something or meeting someone, and by one's attitude towards the unavoidable suffering. 
A pastoral counsellor is looked upon as a person of faith, who is committed and trustworthy (Vaughan 1987:17). The values of God's kingdom are central to pastoral counselling. For people of faith, prayer can be a powerful response to human situations. It is a response of the person as a whole. Prayer is personal and in the deepest sense a dialogue, characterised by surrender. A spiritually mature counsellor grasps that she or he does not carry the full burden of being a healer, but is rather a participant in the process with God (Morgan 1987:150-152). Guidance and counselling are specific aspects of pastoral care (Best, Jarvis \& Ribbins 1977:127). Bay et al. (2008:58) point out that a life of faith could contribute to 'better health, improved coping with medical conditions and reduced morality rates'. Prayer groups and religious support groups can provide people suffering from anxiety and depression, with a sense of belonging and comfort. According to a study by Bay et al. (2008:58) individuals who received pastoral care were better equipped both emotionally and spiritually. Pastoral care includes listening, understanding and building a trusting relationship, as well as treating the person with compassion, dignity and respect (Newitt 2009:893). Pastoral counselling and care help individuals to cope with suffering.

This article explores the role of the pastoral counsellor in helping specifically those affected by domestic violence. This includes understanding their emotions, and disrupted social and spiritual lives which resulted from the trauma they experienced. Counselling can help counsellees to find their way back to healing on a psychological and spiritual level. This healing occurs from within themselves (intra-) and in relationships with others (inter-).

\section{Existing research}

Domestic violence and abuse in South Africa have been investigated by various disciplines. According to a study by Peltzer, Mashego and Mabeda (2003:150,152), one out of every eight women in South Africa is beaten by her partner. Three per cent of these women needed medical help, $4 \%$ became pregnant and $4 \%$ of all the women who reported the abuse had been raped. Reasons indicated were sociological factors, such as alcohol or drug abuse, and the husband's and/or the woman's psychological problems (Peltzer et al. 2003:155). According to Richter (2008:87) most abusers have experienced or witnessed physical or sexual violence directed at their mother. Kubeka (2008:284) finds that in violent domestic situations battered women demonstrate weak parenting skills and do not attend to their children sufficiently because of the strain of being battered. A woman's psychological functioning is increasingly affected by domestic violence.

According to Richter (2008:79) South Africa has a high rate of child abuse, maltreatment of children and rape of infants and toddlers. This takes the form of physical, mental and sexual abuse, and exploitative work and trafficking. It occurs in families, schools, on the streets and also to those who are in the care of the state. Of all the sexual assault cases reported, half are children under the age of 18 (Richter 2008:87). Sexually abused children often know the perpetrator who could be a family member or a friend of the family. The child is at risk because of the adult's strength, the child's obedience, and intimidation. According to Fako (1997:141, 143), child abuse has increased as a result of poverty, a lack of economic support and the disintegration of families.

In his study, Kubeka (2008:282) found that exposure to violence at home during the learning phase of childhood contributes to violent behaviour. It leads to violent relationships, post-traumatic stress and dating violence amongst adolescents. Ideas of male power and control were present in the socialised gendered notions of participants. Violence is often used to affirm masculinity. Kubeka (2008:283) identifies mental problems in adolescents as one of the prevalent consequences of the trauma of domestic violence. Violent behaviour aims to control and induce submissiveness in others. It is difficult to break the cycle of violence. Common psychological problems are fear, confusion and anger. Post-traumatic stress disorder can develop. Concentration problems, shock and general vulnerability to stress as well as the feeling of a loss of control, powerlessness, fear and a lack of security can occur. Problems such as dysphonic (difficulty in speaking) moods, anxiety and a damaged self-image are prevalent (Kubeka 2008:284).

In 1996 the South African Constitution added a section which defines children's right to education, shelter, health and freedom from maltreatment (McQuigg 2010:354; Richter 2008:79). The South African state has taken upon it the obligation to protect women and children from domestic violence and the Domestic Violence Act 116 was passed in 1998.

The article investigates the extent to which legislation has succeeded in protecting individuals. Knowledge of the law and legal recourse can contribute to people working together to develop a safer and more secure society. The model of Richard Osmer (2009:2) will be used as a framework. The first of the four questions of this model is: 'What is going on?' The focus is on attaining knowledge of the phenomenon. The interpretive question is: 'Why is this going on?' This aspect concerns investigating, interpreting or explaining the phenomenon. The pragmatic question is: 'How might we respond?' A plan of action is formed. The fourth is the normative question: 'What ought to be going on?' Theological and ethical perspectives come into play.

The 'what' question with regard to domestic violence is: 'What is going on in South Africa?' Sexual offences are described in the Domestic Violence Act 116 of 1998. Statistics indicate high figures of domestic violence and insufficient knowledge of resources for people who are trapped in a situation of domestic violence. The 'why' question is: 'Why is domestic violence so prevalent in South Africa?' Studies by Kleijn (2010) and Londt and Roman (2009) point to contributing factors such as the patriarchal mindset in South African 
cultures, poverty and the debilitating level of unemployment. The third question on how to respond to the phenomenon of domestic violence prompts the answer that knowledge with regard to how to get help and escape from the cycle of violence, is needed. Information with regard to legal resources can be given at school, clinics and municipalities as well as in public places. Another avenue for receiving help is pastoral care, which is accessible to people in the communities where they live and is inexpensive. The fourth question, 'What ought to be going on?', is addressed from a theological perspective. People should be treated with love and respect as the creation of God. Hope and a meaning of life are central categories in religion and faith and can contribute to a resilient response to adversity, and healing.

\section{South Africa - contaminated by violence}

Much of the violence in South Africa is perpetrated by criminals. However, a large number of violent incidents happen in the home and are perpetrated by family members on family members, including children and young people. Children and young people are often exposed to violence in the home and sometimes they themselves are abused. In the Domestic Violence Act 116 of 1998, domestic violence is described as:

$[A]$ ny controlling or abusive behaviour by a partner which harms, or may cause imminent harm to the safety, health or well-being of a person with whom the abuser is in a domestic relationship. Domestic violence includes physical abuse, sexual abuse, emotional, verbal and psychological abuse, intimidation, harassment, stalking, damage to property and entry into a complainant's residence without consent. (see Meerkotter 2009)

In a South African study on domestic violence, Lezanne Leoschut (2009:2-4) interviewed 4391 young people between the ages of 12 and 22 years with regard to domestic violence and found that the incidence of acts of violent crime against youth is significantly higher than against adults. The 2007 and 2008 National Crime and Victimisation Surveys of violent crimes come to similar conclusions - namely that violent crimes perpetrated against youth are more than double than against adults. The high level of crime and violence that young people experience in their homes corresponds to the general disorder and criminality which characterise the social environment in which the young people live. The use of alcohol from an early age can be associated with alcohol-related violence such as physical and sexual assault amongst youth and adults.

This makes it difficult for children to learn non-violent ways of interacting with others. The violence and abuse to which they are exposed from an early age has a significant impact behaviour later on in life: the victim becomes the perpetrator. A study by Wood, Lambert and Jewkes (2008:43) in a rural Xhosa-speaking context illustrates the role of cultural embeddedness in the prevalence of domestic violence. Deeply embedded in Xhosa culture are techniques of 'disciplining' by men and inequality in the relationship between the sexes. In addition to this, the complexity of South Africa's social and political history has contributed to conditions that lead to various kinds of interpersonal violence. Since the end of apartheid, researchers and policy makers have increasingly focused on girls and young women's experiences of violence in households, including sexual violence.

The study by Wood et al. (2008:44) amongst Xhosa youth includes a survey on physical abuse by a current or expartner. In rural Xhosa-speaking townships, impoverished and economically marginalised areas (agriculturally unproductive and lacking in industry), statistics on violence on women aged between 18 and 49 show that $26.8 \%$ have been physically abused by their partners. Only a third reported their injuries. From a cultural point of view it is expected that a man should be the one in control of the household, making decisions and protecting woman. This 'protection' and 'discipline' can include acts of violence, either provoked by the woman's 'insubordination', or with the aim to resolve conflict (Wood et al. 2008:47). All of this is culturally acceptable and therefore goes unchecked. Children grow up with this example. The boys learn that they will one day do the 'disciplining' and that they are fully entitled to act that way. The girls learn that they will be subjected to this 'disciplining' by males and that is simply the way things are.

The transition of South Africa to democracy has redefined gender and sexuality. This challenges traditional and cultural views of masculinity. The argument that the postapartheid era leaves men with a disempowering sense of irrelevance in the domestic sphere is put forward to explain the level of violence currently experienced in the country (Wood et al. 2008:47). The question is, however, whether this is a valid argument or whether it is a justification of injustice perpetrated against women and children. In precolonial gender relations, Xhosa women were defined by their productive and reproductive function. In such subsistence-based communities the value women brought to a marriage was linked to the value of cattle (lobola). If there was infertility or disobedience on the women's part, it was considered just cause to demand the return of the cattle that had been paid as lobola. In Xhosa families it was expected of the wife to 'be quiet and submissive to the point of helplessness' (Wood et al. 2008:48).

Under colonial rule, the loss of agricultural land, the rise of migrant labour and the development of a cash economy had a further impact on male authority. For the males, participation in a violent lifestyle and the 'instrumental use of aggression against women and girls became one way of wielding power in a racist, capitalist society from which they were excluded' (Wood et al. 2008:49). This was aggravated by the lack of discipline by the elders in the rural communities. In traditional communities structures to protect girls were in place, but with these falling away the girls are left vulnerable to violence (Wood et al. 2008:49). Colonial oppression upset the delicate balance between 'discipline' and 'protection' 
which was maintained in a traditional environment. Without the counteraction of traditional 'protection' the full consequences of such a patriarchal mindset of male control of women, and women's subordination to men, is unleashed on girls and women.

Studies on youth and domestic violence in South Africa illustrate the severity of this countrywide problem. In families where domestic violence is present, violence tends to occur in a specific cycle, called the 'cycle of violence' (Figure 1).

Leonore Walker (1979) developed the Cycle of Violence wheel and indicates the following four stages of domestic violence: the absence of battering; tension building; tension escalating; and the violent episode stage. Domestic violence increases in frequency and severity over time. It is rarely an isolated incident or a one-time occurrence. First the abuser uses words or threats, perhaps humiliation or ridicule. Then the abuser explodes at some perceived infraction and his rage manifests in physical violence. Finally the abuser 'cools off', asks for forgiveness and promises that the violence will never occur again. When the abuser asks for forgiveness, the victim will usually withdraw charges and accept the apology. The abuser's rage will build up again and the violent cycle will be repeated. The Power and Control Wheel (Figure 2) shows how the abuse of power, the emotional abuse and physical violence escalates and how the control of the abuser over the victim increases.

Prevalent in domestic violence are aspects such as intimidation, emotional abuse, isolation, minimising, denying, blaming, child abuse, male privilege, economic abuse, coercion and threats. In their study, Kelleher et al. (2008:378-379) found that psychotic symptoms (including the loss of a sense of reality), such as hallucinations and delusions occur amongst adolescents who were exposed to

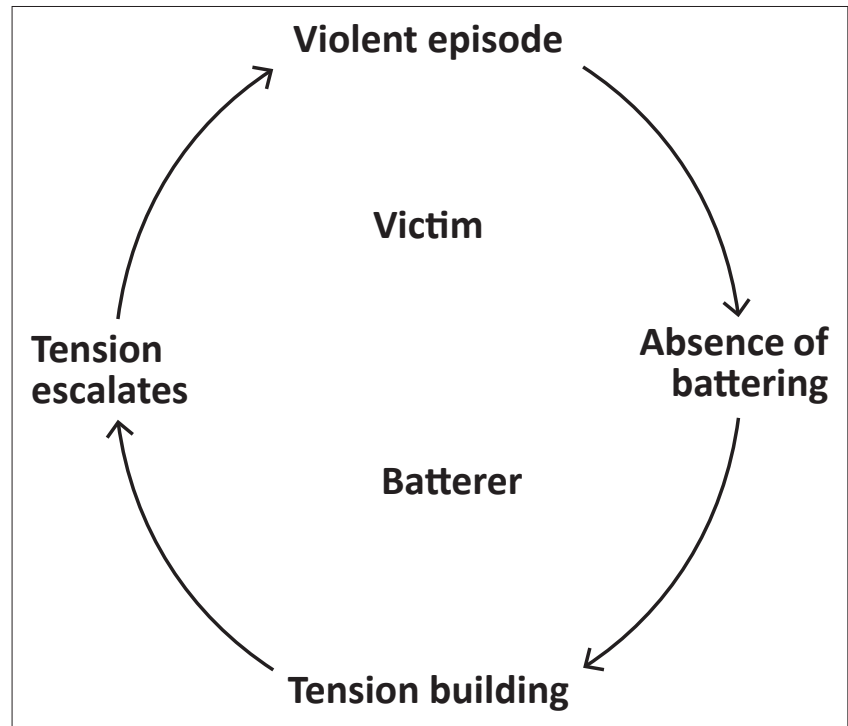

Source: Adapted from Walker, L., 1979, The cycle of violence Micah Projects Inc., viewed 24 January 2014, from http://www.bdvs.org.au/resource_files/bdvas/IR_5_Cycle-of-violencefactshe et.pdf

FIGURE 1: The Cycle of Violence. domestic violence as children. Disorders such as depressive, conduct, phobic, attention-deficit hyperactivity, posttraumatic stress, overanxious, oppositional defiant, tic, and separation anxiety disorder, were identified in the adolescents. A study by K.M. Keyes et al. (2012:107, 110) identified mood, alcohol and drug abuse, and disruptive behaviour disorders, and antisocial behaviour. These findings indicate that victims of domestic violence are at risk of developing emotional disorders later in life.

The following two flow charts demonstrate the possible effects which domestic violence can have on an individual. These flow charts trace the connection between adult emotional disturbances and physical or emotional childhood domestic violence. The flow chart in Figure 3 refers to women and in Figure 4 to men (Keyes et al. 2012:200). They indicate the effects of domestic violence on children. The relationship between maltreatment (on the left) and psychiatric disturbances (on the right) is shown. Internalising and externalising disturbances are distinguished. The internalising group includes two depressive disturbances and five anxiety disturbances. The external disturbances include five noticeable behaviour disturbances.

In summary, domestic violence is clearly a serious concern in South Africa. A contributing factor is the patriarchal mindset still prevalent in many South African cultures. Unemployment is another contributing factor. Few victims of domestic violence have sufficient knowledge of the protection provided by South African law. Domestic violence can lead to possible psychological disturbances in children and adults. Domestic violence unfolds in a cycle of violence which means that those who have been abused in childhood in all likelihood could later become offenders.

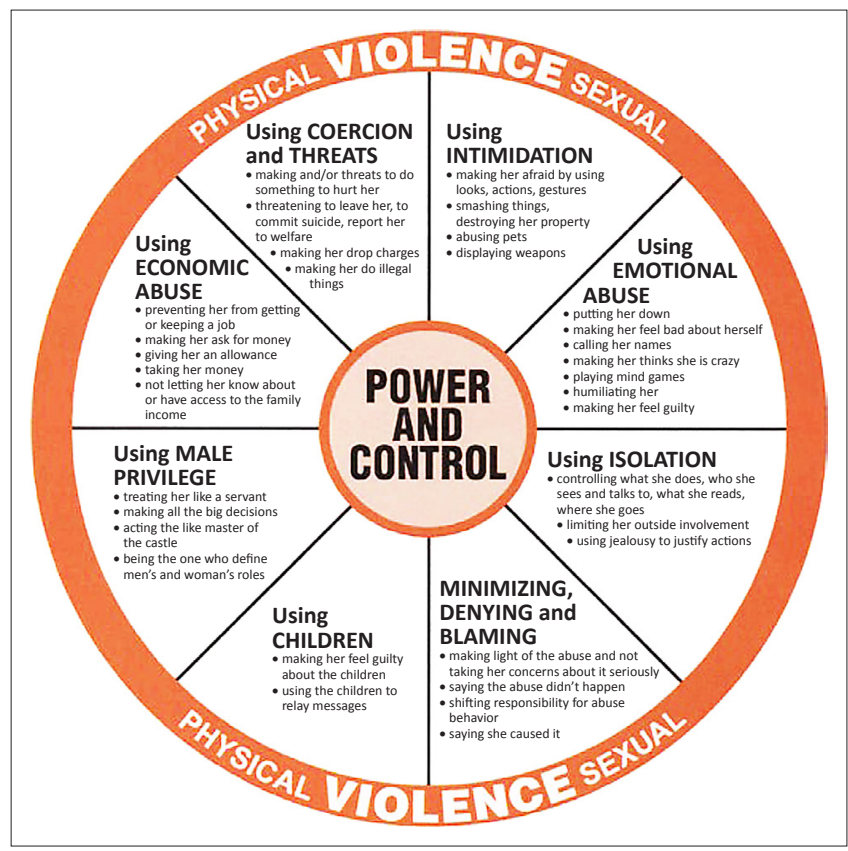

Source: Centre for children and familes in the justices system, n.d., Power \& Control Wheel, viewed 24 January 2014, from www.lfcc.on.ca/HCT_SWASM_5.html

FIGURE 2: The Power and Control Wheel. 


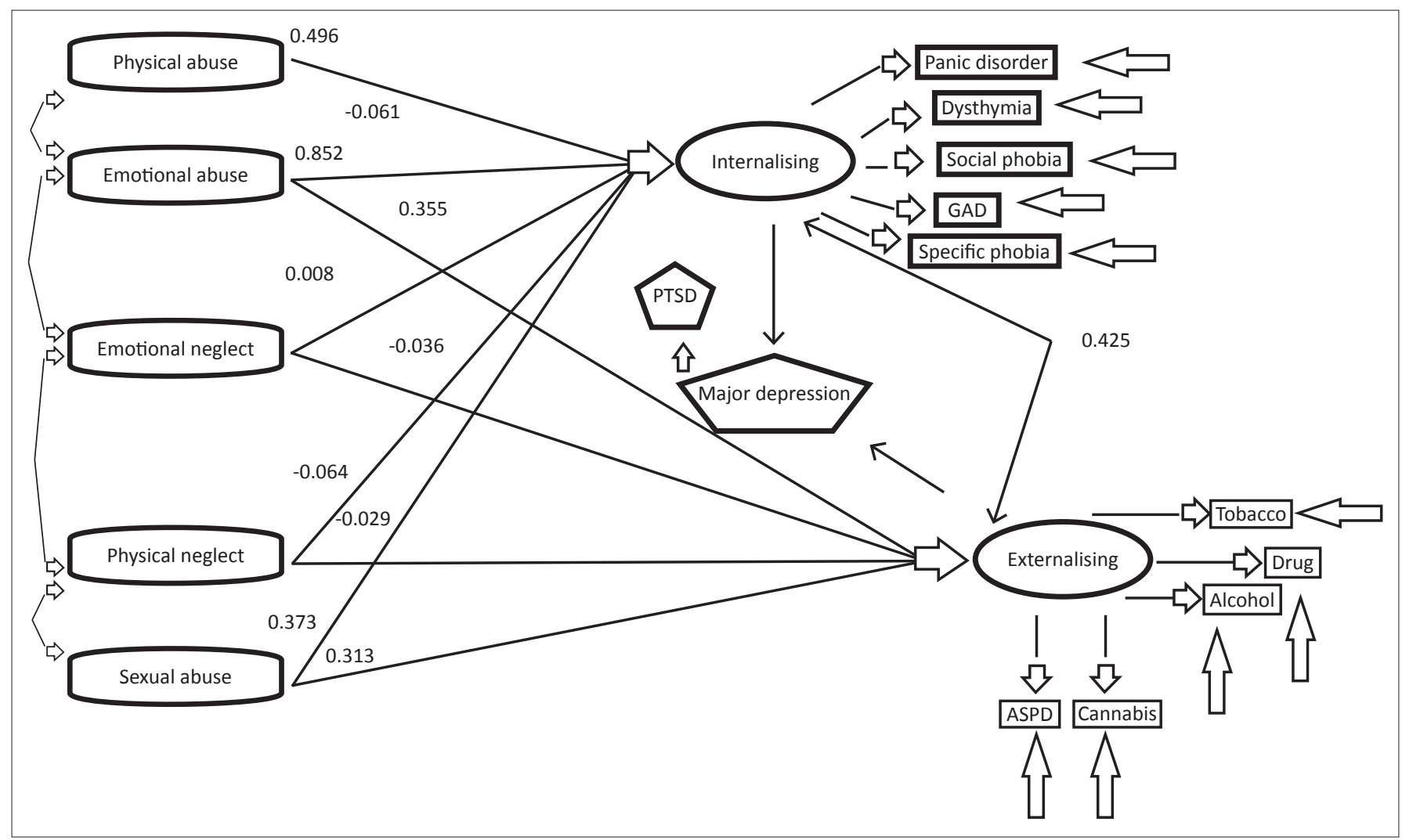

Source: Adapted from Keyes, K.M., Eaton, N.R., Krueger, R.F., McLaughlin, K.A., Wal, M.M., Grant, B.F. et al., 2012,'Childhood maltreatment and the structure of common psychiatric disorders', The British Journal of Psychiatry 200, 107-115. http://dx.doi.org/10.1192/bjp.bp.111.093062

PTSD, post-traumatic stress disorder; ASPD; antisocial personality disorder; GAD, generalised anxiety disorder.

FIGURE 3: Flow chart indicating effects of childhood abuse on women.

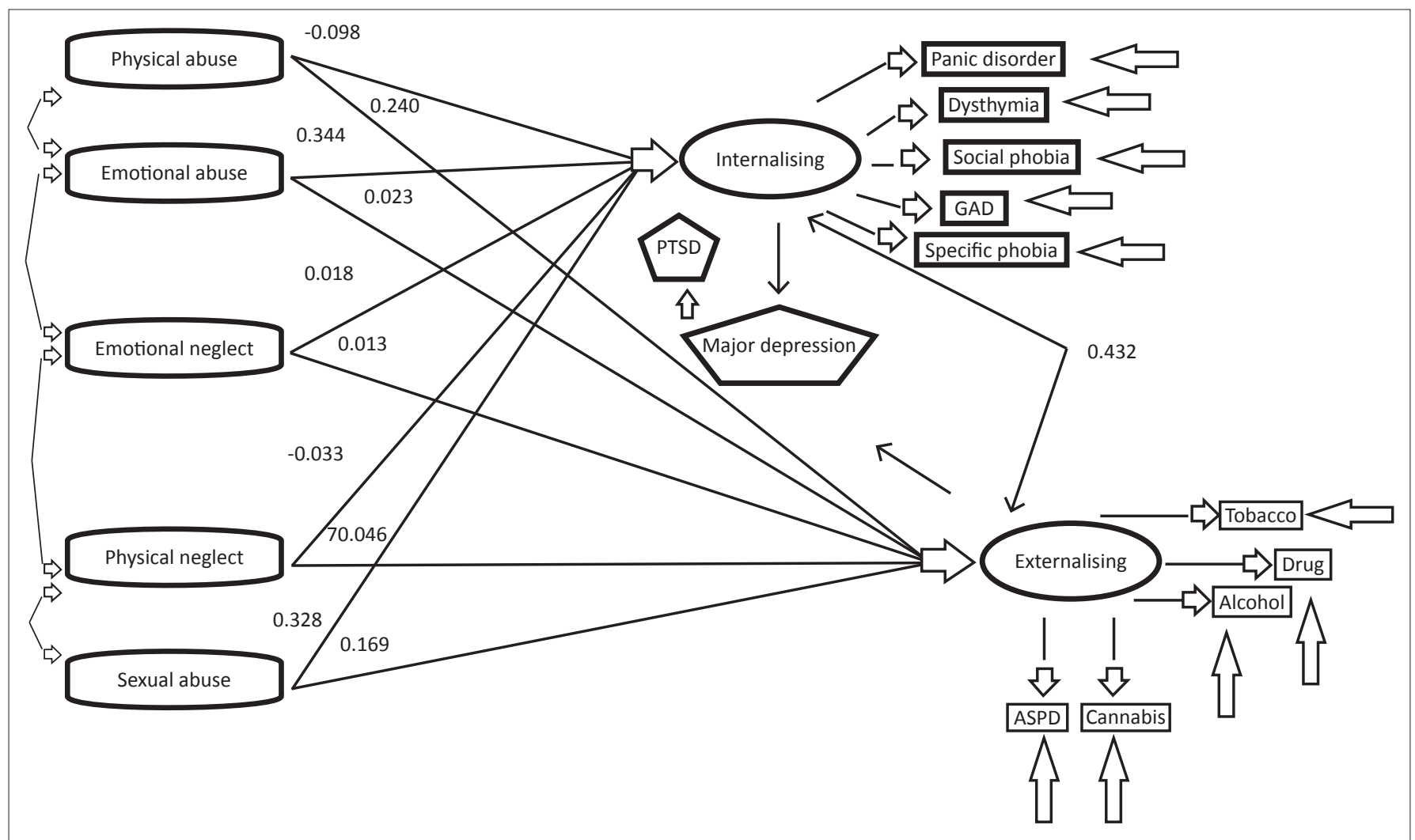

Source: Adapted from Keyes, K.M., Eaton, N.R., Krueger, R.F., McLaughlin, K.A., Wal, M.M., Grant, B.F. et al., 2012,'Childhood maltreatment and the structure of common psychiatric disorders', The British Journal of Psychiatry 200, 107-115. http://dx.doi.org/10.1192/bjp.bp.111.093062

PTSD, post-traumatic stress disorder; ASPD; antisocial personality disorder; GAD, generalised anxiety disorder.

FIGURE 4: Flow chart indicating effects of childhood abuse on men. 


\section{Pastoral psychological approaches Introduction}

Amongst the proliferation of therapeutic methods, some of which will be briefly discussed, narrative counselling and logotherapy are identified as appropriate methods for pastoral care with people who have experienced domestic abuse and struggle to find hope, healing and meaning in life. These two therapy methods are compatible with religious themes such as 'hope' and 'new life'.

Psychologists assist people with troubled lives and dysfunctional relationships to move to a healthier, functioning life and relationships. Pastoral counsellors focus on aspects of faith and spirituality that are central to the frame of reference of people of faith. The points of departure differ. Pastoral counsellors will, for instance, also make use of biblical themes and spiritual devices such as prayer. Some commonalities are to be found. A theme which is of both psychological and pastoral importance is forgiveness. Roberts (2012:38) describes forgiveness as 'directed by one human being (the victim of an offense) to another (the perpetrator of the offense) and the correlate of repenting and asking forgiveness'. On the practical side of the counselling process, the background of the upbringing, and the experiences which form the character and personal disposition of the person, are important. Psychology has long focused on dysfunction, but recently there has been a turn to positive psychology, with the emphasis on growth and flourishing (Roberts 2012:40). With regard to flourishing, aspects such as hope, patience, humility, gratitude and love come into play. This again links up with religious themes such as loving one's neighbour and experiencing the love and power of God.

The terrain of a pastoral counsellor furthermore includes problems of morality, issues of religious diversity and the biological basis of religiosity. Studies have shown that, in general, religious people are healthier (see Ripley 2012:154). Religious practices, beliefs and the social factor of supportive faith communities can contribute to the well-being of people. An approach that includes faith and spirituality can therefore be effective in guiding people to healing. The counsellor seeks to assist counsellees to deal with their problems more effectively (Tan 2011:2). This can be accomplished by involving some form of learning or development (Summers \& Barber 2009; Tan 2011:2).

Psychoanalytic therapy with its focus on the unconscious, Adlerian therapy with its emphasis on individual development and responsibility for life choices, and existential therapy which aims at a meaningful life can provide valuable insights for accomplishing these goals (Tan 2011:4-7). Personal-centred therapy, which has made a large contribution to pastoral care and counselling, assumes that individuals have the capacity for positive development if their environment and relationships are conducive to growth. Therapeutic conditions for growth include congruence or genuineness, unconditional positive regard - which values the client with respect - and accurate empathy. Gestalt therapy focuses on the here and now and integrates the body and mind. Reality therapy focuses on the present time and emphasises people's strengths, being realistic and reaching their goals. Behaviour therapy makes use of techniques such as positive reinforcement and reward for desirable behaviour. Cognitive therapy takes into account how thoughts affect feelings and behaviour. The point of departure of these approaches is that individuals have the capacity to change feelings and behaviours. Amongst the therapeutic approaches that are focused on positive development, two are especially appropriate to pastoral counselling, namely narrative therapy, which makes use of storytelling and logotherapy, which focuses on the meaning to life.

\section{Logotherapy}

Victor Frankl (2004:154), psychologist and holocaust survivor, developed the psychotherapeutic model of logotherapy, which allows the counsellor to enter into the emotional sphere of the counsellee in order to discover new meaning in life (Frankl 2004:104-106). Suffering and difficult circumstances in life can present people with an opportunity to find a deeper meaning in life and transcend their fate. Emotional suffering and the loss of hope can cause people to also lose their spiritual foothold. The meaning of life can be found if people seek answers to the problems of life and fulfil their tasks (Frankl 2004:76-85). The main purpose is never to give up hope. Meaning can also be found in suffering, dying, deprivation and death. Human life is directed towards something, or someone, other than oneself.

The more people serve and love others, the more human they become, transcend themselves and reach self-actualisation. Frankl (2004:115) distinguishes three ways of finding meaning in life: firstly, 'creating a word or doing a deed', which is an achievement or accomplishment; secondly, 'experiencing something or encountering someone', which is finding goodness, truth or beauty in nature or culture, or in loving others in their uniqueness; and thirdly 'the attitude we take towards unavoidable suffering', is what changes personal tragedies or a predicament into a human achievement (Frankl 2004:117). Although suffering is not always meaningful, it is possible to find meaning in the face of suffering. Believers who suffer tribulations in life can draw on their spiritual resources. With Frankl's insights in mind, people who have suffered domestic violence can be guided in pastoral counselling to refocus their attention on finding purpose and meaning in their lives in spite of adversity.

\section{Narrative pastoral counselling}

Both logotherapy and narrative pastoral counselling provide the counsellee with the opportunity to understand the problem by talking about it and by identifying emotions that have led to disturbances. Narrative therapy developed when Ricoeur's (1990a, 1990b) groundwork on narrativity was applied to counselling (Freedman \& Combs 1996; 
Müller 2010; White \& Epston 1990). In narrative the aim is for people to find hope. The stories of the past and memories are searched to discover meaning in life and the individual is guided to develop a new future story (Müller 2010:1-2). Through stories people organise their life in a process of thinking, doing and decision-making. The story discovers and builds identity, which is formed by experiences. Counsellors become involved in the counsellee's story and there is a concerned and empathic movement towards the counsellee's cultural system (Müller 2010:3). Stories contain elements of telling and dreaming. If the gap between the 'telling' and the 'dreaming' increases, maladaptive behaviour can develop. The goal is to create harmony between yesterday, today and tomorrow, and arrive at a space of integrity, wholeness and maturity. Through language persons can reframe the past. Vocabulary and its meanings are the channel through which the counsellee interprets the happenings in her or his life (Müller 2010:1). The counsellor's task is to excavate what lies beneath the story, and help an individual to construct an imagined picture of the future.

In narrative pastoral counselling the narrative of the individual is merged with the story of Christ. The faith narrative contains the promises of God and brings hope. The story of Christ helps the counsellee to find a new future in Christ. The story of the past is re-interpreted in light of the gospel. A 'better future' is a Christian religious motif (e.g. 1 Cor 7) on which hope is based. Where there is hope in God, human struggles need never end in hopelessness. People who have suffered the trauma of domestic abuse can be effectively helped by means of narrative pastoral counselling to work through the events that caused the trauma. Such counselling includes the spiritual aspect of their lives, while covering themes such as guilt, mortality, hope and the grace of God.

\section{Findings}

The high incidence of domestic violence in South Africa necessitates the investigation of this complex issue from a variety of perspectives in order to better understand the phenomenon and provide insights for the prevention of domestic abuse, and the effective caring of the victims. The first source of assistance, the police, often lack the necessary training to respond effectively. People who are abused are not always aware of the legal resources and places of safety that are available to them. Cultural perspectives and practices contribute to the problem of domestic violence which is mostly perpetrated by men who abuse their family for various reasons. Women often accept abuse as the way things are'.

The effect of domestic violence on children includes emotional disturbances that can contribute to a continued cycle of violence in their adult life. Should such disturbances be dealt with adequately at an early stage, there is a better chance of healing which could prevent the individual from becoming a perpetrator of domestic violence later on in life. Adults who are exposed to domestic violence can also develop psychological disturbances. Therapy or counselling can contribute to healing as well as to finding new meaning in life and hope.

The Domestic Violence Act 116 of 1998 should be implemented effectively. Knowledge with regard to the causes, prevention and intervention is needed. The prevalent patriarchal mindset in most South African cultures contributes to abusive behaviour by the men who learn from an early age that they have the rights of power over women and children. In this regard, education is needed. Victims of domestic abuse can develop mental disturbances which can have a detrimental effect on their future life. This requires professional help. Pastors are often the first responders to human need in the communities. However, pastors cannot do it alone. The love and care of the community and faith community is also needed. In order for the faith community to be effective in their support of people who suffer domestic abuse, they should be trained how to respond to abuse and provide help. They should be knowledgeable as to the available resources. The pastor's role can be that of educator.

In order for pastors to respond effectively, they should have an understanding of the dynamics of domestic violence and of the disturbances that can cause. Useful insights for helping people can be drawn from the logotherapy model of Victor Frankl and the narrative approach to pastoral counselling, since both are compatible with religious motifs such as 'new life', 'new beginnings' (alternative future story of the narrative approach), 'hope' and the 'meaning of life and suffering' (logotherapy). These motifs support the values of the kingdom of God as witnessed in the gospel message of hope and new life.

\section{Acknowledgements Competing interests}

The authors declare that they have no financial or personal relationship(s) that may have inappropriately influenced them in writing this article.

\section{Authors' contributions}

This article comprises a reworked rendering of sections of a MA dissertation of P.J.D. (University of Pretoria) with Y.D. (University of Pretoria) as supervisor and G.H. (University of Pretoria) as co-supervisor.

\section{References}

Bay P.S., Beckham D., Trippi J., Gunderman R. \& Terry C., 2008, 'The effect of pastoral care services on anxiety, depression, hope, religious coping, and religious problem solving styles: A randomized controlled study', Journal of Religion and Health 47(1), 57-69. http://dx.doi.org/10.1007/s10943-007-9131-4

Best R.E., Jarvis C.B. \& Ribbins P.M., 1977, 'Pastoral care: Concept and process', British Journal of Educational Studies 25(2), 124-135. http://dx.doi.org/10.1080/00071 005.1977 .9973487

Capps, D., 2010, 'Jesus the village psychiatrist: A summary', HTS Teologiese Studies/ Theological Studies 66(1), Art. \#822, 5 pages. http://dx.doi.org/10.4102/hts. v66i1.822

Centre for children and familes in the justices system, n.d., Power \& Control Wheel, viewed 24 January 2014, from www.lfcc.on.ca/HCT_SWASM_5.html

Collins G.B. \& Culbertson T., 2003, Mental illness and psychiatric treatment: A guide for pastoral counselors, The Haworth Pastoral Press, New York.

De Beer C.S., 2007, 'Filosofiese besinning oor geweld: Uitdagings aan informatiseringstrategieë', Tydskrif vir Geesteswetenskappe 47(4), 3-27. 
Fako, T.T., 1997, Child abuse in Southern Africa, ABSCO Publishing, Gaberone.

Freud, S., [1948] 1964, The complete psychological works, in J. Strachey (ed.), MacMillan, Oxford.

Frankl, V., [1946] 2004, Man's search for meaning, Rider, London.

Freedman, J. \& Combs, G., 1996, Narrative therapy: The social construction of preferred realities, WW Norton, London.

Kelleher, I., Harley, M., Lynch, F., Arseneault, L., Fitzpatrick, C. \& Cannon, M. 2008,'Associations between childhood trauma, bullying and psychotic symptoms among a school-based adolescent sample', The British Journal of Psychiatry 193, among a school-based adolescent sample', The British Jour
378-382. http://dx.doi.org/10.1192/bjp.bp.108.049536

Keyes, K.M., Eaton, N.R., Krueger, R.F., McLaughlin, K.A., Wal, M.M., Grant, B.F. et al., 2012,'Childhood maltreatment and the structure of common psychiatric disorders', The British Journal of Psychiatry 200, 107-115. http://dx.doi. org/10.1192/bjp.bp.111.093062

Kleijn, A.A., 2010, 'The demographic profile and psychosocial history of a group on convicted perpetrators of the rape of children under the age of three years', unpublished PhD thesis, Faculty of Humanities, University of the Witwatersrand.

Kubeka, A.M., 2008, 'Exposure to violence at home: A qualitative exploration of experiences and perceptions of black adolescents', South African Review of Sociology 39(2), 282-300. http://dx.doi.org/10.1080/21528586.2008.10425092

Leoschut, L. \& Burton, P., 2009, 'Building resilience to crime and violence in young South Africans, Research Bulletin Centre for Justice and Crime Prevention $4^{\prime}$, Centre for Justice and Crime Prevention, Cape Town.

Londt, M.P. \& Roman N.V., 2009, 'A descriptive analysis of a child sex offender in Cape Town South Africa', Forensic Psychiatry and Psychotherapies 16(1), 72-73.

McQuigg, R.J.A., 2010, 'How could human rights law be used by the courts to assist victims of domestic violence? A comparative study', The International Journal of Human Rights 14(3), 343-363. http://dx.doi.org/10.1080/13642980802535427

Meerkotter, A., 2009, Domestic Violence, Health and HIV: A review on progress made in addressing domestic violence through the HIV \& AIDS and STI National Strategic Plan 2007-2011, Policy Brief \#3, February 2009, viewed from http:// Strategic Plan 2007-2011, Policy Brief \#3, February 2009,
www.healthlink.org.za/uploads/files/PolicyBriefNSP_LR.pdf

Morgan, O.J. 1987, 'Pastoral counseling and petitioner prayer', Journal of Religion and Health 26(2), 149-152. http://dx.doi.org/10.1007/BF01533686
Müller, J., 2010, 'Intercultural pastoral care and counseling', unpublished reader, Cape Town Baptist Seminary.

Newitt, M., 2009, 'Chaplaincy services are not only for religious patients', British Medical Journal 338(7699), 893.

Osmer, R.R. 2009, 'Practical Theology: A current international perspective', Theological Studies 67(2), 1-7.

Peltzer, K., Mashego, T.A. \& Mabeba, M., 2003, 'Attitudes and practices of doctors toward domestic violence victims in South Africa', Health Care for Women International 24(2), 149-157. http://dx.doi.org/10.1080/07399330390178431

Richter, L.M., 2008, 'Child abuse in South Africa: Rights and wrongs', Child Abuse Review 17, 79-93. http://dx.doi.org/10.1002/car.1004

Ricoeur, P., 1990a, 'Time and narrative', Critical Inquiry 7(1), 169-190. http://dx.doi. org/10.1086/448093

Ricoeur, P., 1990b, Time and narrative, University of Chicago Press, Chicago, IL.

Ripley, J.S., 2012, 'Integration of psychology and Christianity', Journal of Psychology \& Theology 40(2), 150-154.

Roberts, R.C., 2012, 'The idea of a Christian psychology', Journal of Psychology 40(1), 37-40.

Summers, R.F. \& Barber, J.P., 2009, Psychodynamic therapy: A guide to evidencebased practice, Guilford Press, New York, NY.

Tan, S.Y., 2011, Counseling and psychotherapy: A Christian perspective, Baker Academic, Ada, MI.

Vaughan, R.P., 1987, Basic skills for Christian counselors: An introduction for pastoral ministers, Paulist Press, New York, NY.

Walker, L., 1979, The cycle of violence Micah Projects Inc., viewed 24 January 2014, from http://www.bdvs.org.au/resource_files/bdvas/IR_5_ Cycle-of-violencefactshe et.pdf

White, M. \& Epston, D., 1990, Narrative means to therapeutic ends, WW Norton, London.

Wood, K., Lambert, H. \& Jewkes, R., 2008, “Injuries are beyond love”: Physical violence in young South Africans' sexual relationships', Medical Anthropology 27(1), 43-69. 